\title{
Fatal Massive Air Embolism During Holmium Laser Enucleation of the Prostate (HoLEP)
}

\author{
Zhang Wangping, Ren Ming* \\ Email address: \\ zhang650679@163.com (Zhang Wangping), 1910773504@qq.com (Ren Ming) \\ ${ }^{*}$ Corresponding author
}

Department of Anesthesiology, Affiliated Women and Children's Hospital of Jiaxing University, Jiaxing, China

To cite this article:

Zhang Wangping, Ren Ming. Fatal Massive Air Embolism During Holmium Laser Enucleation of the Prostate (HoLEP). Science Journal of Clinical Medicine. Vol. 6, No. 4, 2017, pp. 60-62. doi: 10.11648/j.sjcm.20170604.13

Received: January 15, 2017; Accepted: February 17, 2017; Published: October 18, 2017

\begin{abstract}
Massive air embolism occured during holmium laser enucleation of the prostate (HOLEP) for prostatic hyperplasia (BPH). A 65 years patient with BPH was scheduled to undergo elective HoLEP. After anesthetic of intrathecal 15 mg hyperbaric ropivocaine was administered in the left lateral decubitus position, then the patient was turned in supine position. The surgery started when the patient was placed in a 10 degree head down tilt. Two hours and 40 min later, while the hypertrophic prostate was almost enucleated, the patient complained of abdominal distension. Immediately, he was not breathing and his eyes were glazed. The heart rate abruptly decreased from 82 to 35 beats per min and cardiac arrest happened. After intubation, it showed the end-tidal carbon dioxide partial pressure $\left(\mathrm{PetCO}_{2}\right)$ was $6 \mathrm{mmHg}$. When took a blood sample from external jugular vein for blood gas analysis, some air existed in the syringe. VAE was suspected.
\end{abstract}

Keywords: Air Embolism, Holmium Laser, Prostate

\section{Introduction}

To our knowledge, massive air embolism is a rare but fatal complication during the surgery of prostate. A few cases have been reported during the procedure of transurethral resection of the prostate (TURP), a gold standard treatment for symptomatic benign prostatic hyperplasia (BPH). Compared with TURP, Holmium laser transurethral enucleation of the prostate (HoLEP) provides equivalent improvement for BPH with a relatively bloodless and safe manner. [1] Recently, a case of VAE during HoLEP has been reported. [2] Now we reported the another case occurring in a 65-year-old male.

\section{Case Report}

A 65-year-old patient with BPH was scheduled to undergo elective HoLEP. He underwent a TURP eight years ago, suffered from nasopharyngeal carcinoma a year ago and received chemotherapy for treatment without obvious complications attendant. Examinations showed no cardiopulmonary abnormality. Preoperative ECG and chest x-ray were normal. The remainders of the preoperative testing and laboratory evaluation were unremarkable.

\section{Process}

Upon arrival in the operating room, standard monitoring was established. An 18-G intravenous catheter was placed, and lactated Ringer solution was infused at rate of $6 \mathrm{ml} / \mathrm{kg} / \mathrm{h}$. In the left lateral decubitus position, a spinal anesthetic of 15 $\mathrm{mg}$ hyperbaric ropivocaine was administered without difficulty. The patient was then turned and kept supine for 5 min before being placed in the lithotomy position. The sensory level achieved at T6, blood pressure was 105/66 $\mathrm{mmHg}$, and the pulse was 63 beats per minutes. Fifteen minutes after the injection of the local anesthetic, the surgical procedure began. The patient was placed in a 20 degree head down tilt. HoLEP was performed using a 100W Ho: YAG VersaPulse ${ }^{\circledR}$ Power Suite ${ }^{\mathrm{TM}}$ laser source (Lumenis ${ }^{\circledR}$, Santa Clara, California) with a 550 micron SlimLine ${ }^{\mathrm{TM}}$ end firing laser fiber. Saline $(0.9 \%)$ was used as the irrigation fluid. The surgery proceeded uneventfully to the step of enucleation, and there were no perforations on the prostate capsule or severe bleeding. Two hours and $40 \mathrm{~min}$ later, while the 
hypertrophic prostate was almost enucleated, the patient complained of abdominal distension. Immediately, he was not breathing and his eyes were glazed. The heart rate abruptly decreased from 82 to 35 beats per min. Oxygen saturation as measured by pulse oximetry $\left(\mathrm{SpO}_{2}\right)$ decreased to $92 \%$. He was found rapidly to be pulseless and cardiac arrest, and the blood pressure could not be measured. The operation was stopped at once. The patient was ventilated manually with $100 \% \mathrm{O}_{2}$ via face mask and was intubated with a $7.5 \mathrm{~mm}$ endotracheal tube as cardiopulmonary resuscitation (CPR) was instituted at the same time. After intubation, it showed the end-tidal carbon dioxide partial pressure $\left(\mathrm{PetCO}_{2}\right)$ was $6 \mathrm{mmHg}$. When took a blood sample from external jugular vein for blood gas analysis, some air existed in the syringe. VAE was suspected.

The patient was then placed in a slight head down position with left lateral tilt. The right internal jugular vein was catheterized. Aspiration from the central line catheter yielded about $50 \mathrm{ml}$ of frothy air bubbles. Initial blood gases indicated $\mathrm{pH}$ 6.76, $\mathrm{PaCO}_{2} 110 \mathrm{mmHg}, \mathrm{PaO}_{2} 62 \mathrm{mmHg}$ and oxygen saturation $60.6 \%$. Hemoglobin $(\mathrm{Hb})$ was $11.7 \mathrm{~g} / \mathrm{dl}$. Serum electrolytes and glucose were normal. Then $200 \mathrm{ml}$ sodium hydrocarbonate solution (5\%) was infused. A cooling cap was used for cerebral hypothermia. Approximately 20 min after resuscitation was instituted, the patient's circulation returned to be spontaneous, BP145/96mmHg, HR $88 \mathrm{bpm}$, $\mathrm{SpO}_{2} 96 \%$, PetCO $218 \mathrm{mmHg}, \mathrm{CVP} 7 \mathrm{~cm} \mathrm{H} \mathrm{H}_{2} \mathrm{O}$. The patient's bilateral pupils were symmetric $(2 \mathrm{~mm})$ and the light reflex showed a delayed feedback. Echocardiogram examnation was not taken because that we did not have the required device in the operating room. The patient was then transferred to the intensive care unit (ICU).

In ICU, a chest X-ray was performed and showed signs of pulmonary edema. The lung were auscultated with obvious wheezes and crackles and pink frothy sputum appeared in the endotracheal tube. Mechanical ventilation with positive endexpiratory pressure (PEEP) was established. Oxygenation of the patient was improved 10 minutes after treatment. The patient recovered his spontaneous respiration in 12 hours but still in coma. He was extubated on the fifth day postoperatively. The patient was transferred for hyperbaric oxygen therapy on postoperative seventh day when he could nod his head responsively but was unable to speak. A month later, the patient almost completely recovered and received a second operation successively getting out of the prostate tissues left in the bladder, only accompanied with a sequela of diminished hearing.

\section{Discussion}

HoLEP is a modern alternative to the standard TURP procedure for BPH. This new procedure provides comparable effects with decreased bleeding due to the advantage of Holmium Laser in cutting and coagulation. During HoLEP, surgeons remove the entire portion of the prostate gland, leaving just the capsule in place. However, the operative time is slightly longer than that of TURP. Several cases of venous air embolism during TURP have been reported in literature. Air embolism during HoLEP rarely occurs. Kato $\mathrm{T}$ et al reported the first case of air embolism in HoLEP as a result of incorrect assembly of the morcellator drain system lately. 2 The diagnosis of VAE in our case was confirmed by aspiration of frothy blood through the central venous catheter, as well as by clinical signs such as dyspnea, bradycardia, decreased oxygen saturation, low end-tidal $\mathrm{CO}_{2}$ and pulmonary edema.

Generally, an open venous system and a subatmospheric central venous pressure are necessary for air to get into the venous system. Or the air can be forced in by active pressure theoretically. [3] In this case, several factors result in the happening of VAE. The trendelenburg position causes the operative field to be located above the level of the right atrium. The pressure gradients of just $5 \mathrm{~cm} \mathrm{H}_{2} \mathrm{O}$ can be sufficient to make it prone to VAE when the operative field above heart level. [4] During HoLEP, surgery could still damage the prostatic bed, a rich vascular area, applying an entrance for air to be drawn into the venous system.

The volume of gas entering the venous system are crucial. Air emboli of small size generally has no effect on circulation. Only a small number of cases suffering fatal VAE during prostatic surgery have been reported till now. [5-7] Those cases were detected only because catastrophic hemodynamic and respiratory changes happened. It is estimated that the lethal volume of IV air in human is 3-5 $\mathrm{ml} / \mathrm{kg}$. [8] If the air goes into the right heart with a fast velocity, acute occlusion of pulmonary artery outflow will occur, which may be fatal. Or the air may probably be reabsorbed at the alveolar-capillary interface when the entrainment is slow. [9] Thus, this case suggests a massive and rapid onset of pulmonary air embolism. According to previous literature, air embolism during the surgery of prostate with clear reasons is caused by human error, such as incorrectly assembly of irrigation system [10] or morcellator system, [11] injecting a large amount of air through the Foley catheter. [12] In most cases, however, the source of air is unclear. To our suspect, it is most possible in this case that the air is pushed into the bladder because of the urologist intermittently extracting and inserting the scope from the sheath in a high frequency during surgery. We exclude the possibility referred to by Chang CP [13] that bubbles seen during Ho: YAG laser lithotripsy could result in embolism because these bubbles are formed by water vapor when the water absorbs laser energy. It is air emboli, largely composed of relatively insoluble nitrogen, that are more likely to result in clinically significant cardiopulmonary events. Also, another possibility that air could have entered the bladder through the irrigation bag is eliminated under the condition of vigilant care by the nurse. However, we have no way of tracing the source of gas. This report represents an extreme case survives massive air embolism, quite similar to the case undergoing TURP reported by Tsou MY et al [14] exception of the outcome. The difference can be attributed to the younger age of patient. Aspirating air from the heart and effective CPR are crucial to the successive resuscitation of 
outpatient. Therefore, during the surgical procedures for $\mathrm{BPH}$, whether it is TURP or HoLEP, venous air embolism should be payed more attention to. Besides, massive emboli, less spectacular air emboli may occur more commonly. Hong JY et al [15] recently reported that up to $80 \%$ of cases were found embolis in their heart during radical retropubic prostatectomy when transoesophageal echocardiography (TOE) was used for monitoring. For this reason, we suggest close monitoring for possibly VAE during the surgery of prostate, especially for the eldly atient or those who have cardiopulmonary comorbidities. Since all clinical changes of VAE are rarely consistently positive, transesophageal echocardiography, the most sensitive method for detection of air in the heart, is recommended as the routine monitoring item.

\section{Conclusion}

When the patient complained of abdominal distension accompany with the heart rate, blood pressure and $\mathrm{SpO}_{2}$ rapidly decreased, air embolism maybe occur during holmium laser enucleation of the prostate (HOLEP) for prostatic hyperplasia (BPH).

\section{References}

[1] Aho TF. Holmium laser enucleation of the prostate: a paradigm shift in benign prostatic hyperplasia surgery. Ther Adv Urol 2013, 5: 245-53.

[2] Kato TI, Sugimoto M, Matsuoka Y, et al. Case of vascular air embolism during holmium laser enucleation of the prostate. Int J Urol 2014, 13.

[3] Vacanti CA, Lodhia KL. Fatal massive air embolism during transurethral resection of the prostate. Anesthesiology 1991, 74: $186-7$

[4] Albin MS, Carroll RG, Maroon JC. Clinical considerations concerning detection of venous air embolism. Neurosurgery 1978, 3: 380-4.

[5] Albin MS, Ritter RR, Reinhart R, et al. Venous air embolism during radical retropubic prostatectomy. Anesth Analg 1992, 74: $151-3$.

[6] Memtsoudis SG, Malhotra V. Catastrophic venous air embolus during prostatectomy in the Trendelenburg position. Can J Anaesth 2003, 50: 1084-5.

[7] Tsou MY, Teng YH, Chow LH, et al. Fatal gas embolism during transurethral incision of the bladder neck under spinal anesthesia. Anesth Analg. 2003, 97: 1833-4.

[8] Toung TJ, Rossberg MI, Huthins GM. Volume of air in a lethal venous air embolism. Anesthesiology 2001, 94: 360-1.

[9] Presson RG, Kirk KR, Haselby KA, et al. Fate of air emboli in the pulmonary circulation. J Appl Physiol 1989, 67: 1898-902.

[10] Frasco PE, Caswell RE, Novicki D. Venous air embolism during transurethral resection of the prostate. Anesth Analg 2004, 99: 1864-6.

[11] Kato T, Sugimoto M, Matsuoka $Y$, et al. Case of vascular air embolism during holmium laser enucleation of the prostate. Int J Urol. 2015, 22: 227-9.

[12] Vacanti CA, Lodhia KL. Fatal massive air embolism during transurethral resection of the prostate. Anesthesiology 1991, 74: $186-7$

[13] Chang CP, Liou CC, Yang YL, et al. Fatal gas embolism during ureteroscopic holmium: yttrium-aluminium-garnet laser lithotripsy under spinal anesthesia - a case report. Minim Invasive Ther Allied Technol 2008, 17: 259-61.

[14] Tsou MY, Teng YH, Chow LH, et al. Fatal gas embolism during transurethral incision of the bladder neck under spinal anesthesia. Anesth Analg. 2003, 97: 1833-4.

[15] Hong JY, Kim JY, Choi YD, et al. Incidence of venous gas embolism during robotic-assisted laparoscopic radical prostatectomy is lower than that during radical retropubic prostatectomy. Br J Anaesth 2010, 105: 777-81. 